\title{
La transición escolar como reto en el proceso formativo de los niños y niñas*
}

\author{
School transition as a challenge in the learning process of boys and girls \\ Bairon Jaramillo Valencia ${ }^{\circledR}$, Verónica Benítez Berrio² ${ }^{2}$ Katherine Castro Díaz ${ }^{3}$
}

Para citar este artículo: Jaramillo, B., Benítez, V. y Castro, K. (2020). La transición escolar como reto en el proceso formativo de los niños y niñas. Infancias Imágenes, 19(1), 9-20

\section{Resumen}

El propósito del presente artículo aborda diferentes aspectos de la transición escolar y su influencia en el desarrollo formativo de los estudiantes que pasaron del grado transición al grado primero de básica primaria. Se explayan, además, los conceptos derivados del proceso de transición y, a su vez, la influencia sobre la cotidianidad del ambiente escolar; se resaltan en este último las características principales de los estudiantes, así como sus habilidades sociales y comunicativas. Por otra parte, esta investigación cualitativa apuntó a un enfoque descriptivo tomando el estudio de caso como opción metodológica; de igual forma, utilizó unas técnicas y herramientas para la recolección de información (entrevista semiestructurada, análisis documental y observación no-participante). Este artículo fue uno de varios productos provenientes de la investigación titulada "La transición escolar y su incidencia en las habilidades sociales", en la cual participaron la Universidad Católica Luis Amigó y la Fundación Colegio San Juan Eudes.

Palabras clave: transición, formación, educación, infancia.
Recepción: 2019-06-11

Aprobación: 2019-09-17

\begin{abstract}
The aim of this article is to approach different aspects regarding school transition and its influence in the learning development of students who passed from preschool level to elementary first grade; moreover, some concepts about the transition processes are explained, as well as their influences in the usual school environment; by highlighting in these ones, the main characteristics of students, social skills and communicative ones. Besides, this qualitative research points out to a descriptive approach, having the case study as a methodological choice. This study applied a set of techniques (an observational scale, and interview and interactive techniques. This article emerged from a research named 'school transition and its influence in social skills'; evenly, some institution participated in it: Universidad Católica Luis Amigó and Fundación Colegio San Juan Eudes.
\end{abstract}

Keywords: transition, training, education, childhood.

* Este artículo es derivado de una investigación que llevó como nombre "La transición escolar y su incidencia en las habilidades sociales", financiado y ejecutado con el apoyo de la Universidad Católica Luis Amigó y la Fundación Colegio San Juan Eudes, durante los meses de agosto del 2017 a mayo del 2018.

1 Licenciado en Educación y Humanidades con Énfasis en inglés, Especialista en TIC en la Educación, Magister en Educación con Especialidad en Educación Superior, $\mathrm{PhD}(\mathrm{C})$ en Educación con Especialidad en Investigación, Universidad Católica Luis Amigó. Correo electrónico: bairon.jaramillova@amigo.edu.co.

2 Profesional en Educación preescolar, Universidad Católica Luis Amigó. Integrante del semillero Letras y Voces. Correo electrónico: verónica.benitezbe@amigo.edu.co.

3 Profesional en Educación preescolar, Universidad Católica Luis Amigó. Integrante del semillero Letras y Voces. Correo electrónico: martha.castrodi@amigo.edu.co. 


\section{Introducción}

Las transiciones escolares hacen parte ineludible del proceso escolar: des en ellas que el estudiante logra ascender en su formación académica, cumpliendo con los parámetros establecidos de promoción según la autonomía de cada campo educativo. A pesar de ser un hito importante en la vida de cada individuo, se ha convertido en una rutina subvalorada y sin mayor transcendencia en las instituciones educativas, llegando a ignorar la significación que poseen estas transiciones en aspectos tan puntuales y necesarios como las habilidades comunicativas de los estudiantes y, de igual manera, en los padres de familia.

Este artículo comprende el problema de la transición escolar de educación inicial a básica primaria; abordando situaciones inherentes al aula de clase, dentro del transcurso de adaptación al nuevo grado. Asimismo, la influencia que posee el acompañamiento familiar para lograr una transición exitosa.

Sobre el problema de investigación se establece que en el contexto escolar los niños y niñas fortalecen diversos procesos relacionados con su desarrollo, entre ellos las habilidades sociales; las cuales potencian competencias necesarias a lo largo de la vida escolar. Sin embargo, en el periodo de transición de educación inicial a básica primaria se presentan cambios que influyen en el desarrollo de dichas habilidades, los cuales inciden directamente en el proceso de enseñanza-aprendizaje de los estudiantes.

Características como el aumento en la carga académica al momento de ingresar al grado primero (la cantidad de los contenidos es mayor si se compara con el grado preescolar), y la implementación metodológica del trabajo en el aula. Es decir, las clases magistrales, las actividades individuales y las exposiciones permanentes —además de la poca escucha activa y la baja tolerancia a la frustración que poseen los alumnos- forman parte de algunos de los cambios que se presentan durante este proceso de transición, lo que interviene explícitamente en el proceso social del individuo.

En consecuencia, se presenta una cierta limitación que puede afectar directa o indirectamente las habilidades sociales, ya que al pasar de un ambiente en el cual la mayor parte del tiempo se trabaja en conjunto a otro mucho más individualizado hay una inexorable disminución de la cooperación grupal, convirtiendo los espacios para compartir y expresarse libremente en zonas condicionadas por lo que dicta el nuevo contexto escolar.

Dicha situación se presenta específicamente en una primera división que se da entre la educación inicial y la educación primaria, separando a las instituciones educativas dentro de sus mismas instalaciones. Por una parte, se delimita un espacio para grados como pre jardín, jardín y transición (pertenecientes a preescolar) con un ambiente amigable y con objetos Ilamativos y agradables para los estudiantes, así como espacios dispuestos para jugar y divertirse mientras aprenden; lo que hace que el primer acercamiento al mundo educativo se presente como una experiencia amena. Por otra parte, está la primaria, en ella las áreas del conocimiento son preestablecidas gubernamentalmente; además, cada estudiante tiene una mesa y una silla en las que se harán cargo de sus tareas y donde el juego pasa a ser parte - en mayor medida- de los descansos, logrando así que el acercamiento con el primer nivel de básica primaria sea un lanzamiento repentino hacia la aceptación de mayores y rigurosas responsabilidades tanto académicas como sociales.

Así, en esta investigación se pretende indagar sobre ¿qué incidencia tiene el proceso de transición de educación inicial a básica primaria en las habilidades sociales de los niños y niñas entre 5 y 7 años de edad de la Fundación Educativa Colegio San Juan Eudes, de Medellín, en el 2018? Se toman como categorías de análisis los conceptos de proceso de transición y habilidades sociales.

El presente es el objetivo general que guio el proceso investigativo: identificar la incidencia que tiene el proceso de transición de educación inicial a básica primaria en las habilidades sociales de los niños y niñas entre los 5 y 7 años de edad de la Fundación Educativa Colegio San Juan Eudes en el 2018. A su vez, para llegar a ello se establecieron como objetivos específicos: 1) describir el proceso de la transición de educación inicial a básica primaria; 2) caracterizar las habilidades sociales en los niños y niñas de educación inicial a básica 
primaria; y, por último, 3) determinar la relación entre el proceso de transición de educación inicial a básica primaria y su incidencia en el desarrollo de habilidades sociales.

En primera instancia, se hace necesario conceptualizar algunos términos específicos de la línea educativa que serán indispensables en el desarrollo de este texto. Por ello, se empezará por desglosar el término proceso de transición y toda la influencia que desprende en el ambiente escolar, con el fin de identificar el efecto que ejerce tanto en el estudiante como en todos los participantes que conforman a la comunidad educativa.

\section{Fundamentación teórica}

\section{Transición escolar}

Las transiciones o procesos de transición, generan modificaciones en diversas etapas de la vida. Según Rodríguez y Álvarez, "Dichas transiciones representan un sinfín de experiencias, recuerdos y situaciones definitivas en los esfuerzos por integrarse a un nuevo grupo, en un nuevo ambiente, trascender en momentos críticos, experimentar cambios y, más aún, tener la capacidad de generarlos" (2018, p. 68). Desde la perspectiva psicológica se evidencian cambios en los comportamientos, las emociones, percepciones o sentimientos; y de igual manera, en la perspectiva sociológica, en cuanto a las relaciones interpersonales, el contexto o formas de vida. Estas están enmarcadas en situaciones que comprenden cambios de ambientes; por ejemplo, la transición de un niño del hogar a su primer encuentro con el preescolar supone un enorme cambio de paradigmas y pensamientos para el sujeto (Bustamente et al., 2019). De igual manera, en la transición del preescolar a la básica primaria, momento en el cual el niño deberá no solo modificar ciertas perspectivas sino que además tendrá que transformar su personalidad para lograr un proceso adaptativo al nuevo entorno:

La transición escolar supone pasar de una etapa a otra, tener otras exigencias, desenvolverse en un ambiente nuevo. Pero no necesariamente este proceso debe ser traumático para el niño de preescolar al pasar al primer grado de Educación Primaria. No existe razón alguna para hacer madurar a los niños(as) de manera violenta, ni para exigirles que cambien repentinamente al pasar de etapa; ya que, se debe tomar en cuenta que la evidencia científica determina que los primeros niveles de educación son críticos para desarrollar acciones que influirán en forma determinante en el desarrollo posterior del niño(a), tanto en sus facultades físicas, mentales, como en la personalidad. (Ortiz, 2015, p. 53)

Por esto, es indispensable que el docente, tanto de preescolar como de primaria, logre adaptarse a las necesidades de los infantes con el fin de propiciar en ellos, principalmente, seguridad y confianza; aspectos más que fundamentales para una adecuada integración en un nuevo ambiente y contexto que representará, evidentemente, experiencias de todo tipo por vivir (Peñuela, 2013). Lo anterior, con el fin de dar el paso a la creación de ambientes de aprendizaje significativos, que potencien habilidades y capacidades que ayuden en el proceso de adaptación durante las transiciones escolares, haciendo que el paso entre los niveles sea una oportunidad de crecimiento y cada vez menos notorio:

La transición entre etapas, plantea de forma explícita la necesidad de articular tanto de forma horizontal como vertical la práctica docente, favoreciendo una transición gradual, segura y positiva de los niños a lo largo del sistema educativo escolar contemplando la visión de todos los agentes implicados en el proceso de transición escolar. (Castro et al., 2017, p. 99)

Asimismo, es pertinente que la adaptación durante el nuevo grado se presente desde la institución hacia los estudiantes. Es decir, se deben realizar todas las modificaciones posibles en pro de las exigencias de cada niño, pues es la educación la que debe moldearse según el contexto en el que se encuentre. Por esto, el papel docente es de vital importancia durante el proceso de transición, debido a que es este quien identifica los inconvenientes que puedan tener los estudiantes en esta nueva etapa y los interviene a la menor brevedad posible.

Sobre la base de las consideraciones anteriores es evidente, entonces, que los cambios o 
transiciones son necesarias tanto en la vida personal como en el ambiente escolar. Para dar una mejor explicación de estos planteamientos es pertinente citar a Vloger et al., quienes afirman que:

Las transiciones son los acontecimientos y/o procesos clave que ocurren en períodos o coyunturas específicos a lo largo del curso de la vida. Suelen estar vinculados con cambios que se producen en el aspecto, las actividades, la condición, los roles y las relaciones de una persona, además de las transformaciones relacionadas con el uso del espacio físico y social y/o las modificaciones en el contacto con las convicciones, discursos y prácticas condicionados por la cultura, especialmente cuando dichas modificaciones tienen que ver con cambios de ambiente y, a veces, del idioma predominante. (2008, p. 12)

En el ámbito educativo se viven continuamente estos procesos de transición, siendo símbolo de alteración en algunos factores de los estudiantes, los cuales influyen en la formación del ser. Estos cambios hacen parte del proceso evolutivo de los niños y niñas, en el cual la escuela cumple un papel protagónico al estructurar dicho proceso mediante niveles educativos. Lo anterior supone una característica esencial de la escolarización, donde además de preparar académicamente se pretende fortalecer las capacidades de adaptación a nuevos entornos y las habilidades tanto cognitivas como sociales que se generan durante los cambios que ocurren a lo largo del desempeño escolar. El ejemplo antes descrito es compartido por Dunlop y Fabian, los cuales retoman recientemente el tema de las transiciones y las definen como:

El cambio que hacen los niños de un lugar o fase de la educación a otro a través del tiempo y que representan desafíos desde el punto de vista de las relaciones sociales, al estilo de enseñanza, el ambiente, el espacio, el tiempo, los contextos de aprendizaje y el aprendizaje mismo, haciendo del proceso algo intenso y con demandas crecientes. (2007, p. 74)

En otras palabras, se puede identificar este cambio como un reto hacia los estudiantes, pues les va a exigir una transformación frente a nuevos conocimientos y situaciones, partiendo desde sus saberes previos. Es necesario tener en cuenta que, para un tránsito exitoso, se debe contar con las herramientas adecuadas para que dicha transición sea vista como un desafío a superar de manera tranquila y paciente, adaptada a las necesidades y requerimientos de los niños y niñas.

Así pues, San Fabián (2007) articula las transiciones desde su influencia en el currículo, el cual es el encargado, entonces, de regir todos los procesos educativos que se lleven a cabo en una institución, y debe prever entonces las necesidades y oportunidades que los niños y las niñas estén demandando. Por esta razón, los procesos de transición deben ir ligados al currículo y apostar a un mismo objetivo. Asimismo, las define como:

Una parte consustancial del sistema escolar, donde avanzar supone un conjunto de escalones o niveles que responden a la propia organización del sistema educativo, que estructura divisiones o parcelas, más o menos arbitrarias, en el conocimiento, en los horarios, en los alumnos, en los profesores. (p. 2)

Para este mismo autor, estas transiciones son bien vistas como ritos de pasaje, el cual simboliza un reajuste de la cultura al cual se somete el estudiante e implica "cambio de ambiente, la apertura de nuevas posibilidades, cambio de estatus y un sentido de progresión" (p. 2). Este autor reflexiona, junto con otros autores mencionados anteriormente, que este cambio es una apertura a situaciones de crisis, pues desata inseguridades o incomodidades.

Una jornada de sensibilización frente a este nuevo cambio logrará disminuir la ansiedad que se puede generar ante esta situación, ya que los niños desconocen la mayoría de aspectos a los que se enfrentarán en el próximo grado; siendo esto, un elemento puntual para que su proceso de adaptación sea un poco más difícil.

\section{Proceso formativo}

Durante la formación académica existen diferentes procesos encargados de garantizar los objetivos de la educación, los cuales se relacionan con el generar en los estudiantes aprendizajes significativos 
que se adapten a cualquier contexto en el cual puedan estar inmersos, ya sea personal, laboral, institucional, etc. Los procesos formativos son los que permiten la reconstrucción de conocimientos adquiridos anteriormente; en otras palabras, la transformación de saberes previos. Este proceso busca, en este sentido, moldear y potenciar el aprendizaje del individuo, partiendo de unas bases preobtenidas a lo largo de su vida. Según Turra "Desde la lógica de las racionalidades técnicas del currículum los procesos formativos son vistos como una serie de mecanismos que, bajo procedimientos secuenciados, pretenden alcanzar los conocimientos que se establezcan como necesarios para desarrollar y reproducir en los estudiantes" (2017, p. 25). Para dar inicio a un proceso formativo es necesario establecer un programa adecuado para su ejecución; como, por ejemplo, las metas y objetivos que se quieren lograr, el orden cronológico de las intervenciones necesarias para ello, el contexto y, claramente, determinar a quién va dirigido.

Ahora bien, el proceso formativo tiene una gran fuerza durante el proceso educativo, ambos suelen ser complementarios; $y$, por ende, no puede existir el educativo sin el formativo. Para generar un proceso formativo se necesita de la interacción entre diferentes elementos como: el contexto, el sujeto mismo, los recursos y el entorno; los cuales logran impulsar aún más dicho proceso. Perafán plantea un punto más sobre la importancia y pertinencia: "Los procesos formativos son fuerza activa y propulsora en el acto educativo. Su valor epistemológico muestra una práctica pedagógica juzgada, postulada a priori rutina y mecanización, organización esquemática y simple medio de expresión" (2004, p. 29). Este proceso se instaura más allá de los fundamentos, principios y métodos del conocimiento humano, para crear una nueva estructura de los mismos e ir formándose según lo planificado.

Por lo anterior, los procesos formativos comprenden una parte significativa durante toda la vida del individuo en el contexto tanto educativo como personal, pues es necesaria la presencian de estos procesos para acceder y comprender nueva y oportuna información ante cualquier escenario que requiera la enseñanza y el aprendizaje de nuevos conocimientos. Por lo cual, un óptimo proceso formativo:
[...] se hace a partir de procesos educativos contextualizados y situaciones de aprendizaje centradas en sus entornos, así como creando conexiones con el contexto donde estén involucrados, docentes, directivos, padres-madres, familiares, vecinos, compañeros y agentes educativos externos, gestores de procesos formativos, en un espacio donde se entretejen saberes, con la dinamización de estos, para ser compartidos con los infantes. (López, 2013, p. 54)

Los seres humanos tienen un derecho constitutivo denominado educación, y dicha acción se materializa a través de los procesos. Estos procederes son visibles en escenarios como la sociedad, el hogar y la escuela; y, en esta última, recae gran parte de la responsabilidad por razón de percepciones sociales masificadas, las cuales tienden a atribuir lo bueno y lo malo a esta entidad. Es cierto que la escuela como referente educacional fue creada con dicho fin, más cognoscitivo que comportamental para ser precisos; sin embargo, parece ser que la formación en valores dependiera de igual forma -única y exclusivamente- de dicha comunidad educativa. Por lo cual, es comprensible que se les exija calidad educativa a las instituciones educativas; no obstante, el derecho que los niños y niñas tienen de ser educados se extrapola a otros ambientes como la familia y hasta la misma sociedad (Bácares, 2018).

Por otro lado, se hace referencia a que un proceso formativo de calidad debe, incuestionablemente, trabajar dimensiones cuando se habla de primera y segunda infancia, o competencias transversales cuando se refiere a niveles posteriores. Esto con el fin de "formar" seres humanos versátiles y capaces de enfrentarse a los retos que representa la vida en sí, pues no basta con posibilitar una educación enfocada estrictamente en el conocimiento, ya que probablemente dichos saberes serían aplicados en un futuro a fines no muy loables. Sobre este aspecto, Legañoa et al. establecen que:

La interdisciplinariedad es un acto de cultura y no una simple relación entre sus contenidos; su esencia radica en su carácter educativo, formativo y transformador en la convicción, actitudes y valores de los sujetos del proceso formativo. Es una manera de pensar y actuar para resolver problemas complejos y cambiantes 
de la realidad, con una visión integradora del mundo, en un proceso basado en las relaciones interpersonales de cooperación y respeto mutuos. (2018, p. 493)

Para finalizar, los procesos formativos son la piedra angular de la educación. Sin una apropiada ejecución del proceder docente, del acudiente en el hogar, o de los medios de comunicación, se haría visible dicha desarticulación en el momento en que el sujeto enfrenta los retos del día a día. Por lo tanto, los procesos formativos son una responsabilidad de todos y no solo de la escuela.

\section{Diseño y metodología de la investigación}

La investigación cualitativa se planteó desde una naturaleza descriptiva, la cual permitió, para el estudio base en la escritura de este artículo, especificar las propiedades de un fenómeno en particular. En este caso, las implicaciones de la transición escolar en el proceso formativo de las unidades de análisis que participaron en esta investigación. Consecuentemente:

Con el enfoque cualitativo es posible asumir lo vivencial para estudiar los objetos geográficos en los lugares donde ocurren y explicar los sucesos en atención a los planteamientos personales de sus habitantes. Así se puede interpretar la realidad con una acción geográfica retrospectiva, cuyo propósito es descifrar la evolución geohistórica de la comunidad. (Rivera, 2018, p. 37)

Asimismo, como opción metodológica la investigación acogió el estudio de caso, teniendo como base la cultura y el clima institucional Ilevado a las aulas de clase. Esta perspectiva metodológica posibilitó el análisis de la situación-problema en un espacio-tiempo determinado. A su vez, "la finalidad del estudio de caso es conocer cómo funcionan todas las partes de dicho caso, para crear hipótesis. Los estudios de caso permiten alcanzar niveles explicativos de supuestas relaciones causales encontradas" (Valdivia et al., 2018, p. 31).

En este proyecto fueron participes un total de 20 estudiantes: niños y niñas entre los 6 y 7 años de edad, quienes pasaron del grado transición a primero de básica primaria de la Fundación Educativa Colegio San Juan Eudes, Medellín, Colombia. La selección de esta muestra se hizo de forma aleatoria (no probabilística); por lo cual, de tres grupos se escogió uno, y de dicho grupo se trabajó con el número de estudiantes señalado. De forma adicional, una profesora de educación inicial y dos de básica primaria también fueron incluidas en el estudio con el fin de responder preguntas realizadas por el equipo investigativo.

Para la recolección de la información se aplicaron diferentes técnicas e instrumentos. En primer lugar, una sesión de entrevistas semiestructuradas a los docentes referidos, con el objeto de describir -basándose en sus percepciones y experienciacómo los niños y niñas realizaban el proceso de la transición de educación inicial a básica primaria. En segundo lugar, una revisión documental (informes pedagógicos de educación inicial), cuyo fin fue el caracterizar las habilidades sociales en los niños y niñas de educación inicial a básica primaria. Y, por último, sesiones de observaciones no participantes para determinar la relación existente entre el proceso de transición de educación inicial a básica primaria y su incidencia en el desarrollo de habilidades sociales.

Para el proceso de análisis, en primer término, se diseñó una matriz de recolección de información, en la cual se consignaron los testimonios de las docentes, los informes pedagógicos de los estudiantes y los reportes de las sesiones de observación. Acto seguido se codificó la información recolectada con paleta de cuatro colores - basándose en las categorías de la investigación - en una matriz categorial desarrollada en Excel. Finalmente, se triangularon los resultados pertinentes y redundantes entre la información proveniente de las técnicas y las categorías para dar cabida a los hallazgos que se presentan en este texto.

De la misma forma, se dan a conocer algunas categorías ligadas este estudio con el fin de ofrecer mejor comprensión a los lectores. Es imperativo mencionar que estas categorías son de carácter primario y nacen durante el planteamiento del problema, el cual se suscitó mientras se desarrolló el contacto del equipo investigativo con el contexto 
escolar seleccionado, previo a realizar los trámites para llevar a cabo el estudio:

- Metodología puesta en marcha en el colegio que permite la adecuada transición de un grado a otro.

- Estrategias implantadas que impactan en el paso de un grado a otro.

- Conocimiento epistemológico por parte de maestras sobre la transición escolar.

- Características comportamentales que definen a estudiantes de primero de primaria.

- Criterios para promoción de estudiantes de transición a primerio de primaria.

- Adaptabilidad de los estudiantes a los nuevos ambientes escolares característicos del grado primero de primaria.

- Diferencias entre enfoques educativos y "materias" enseñadas en transición y primero de primaria.

\section{Discusión de los resultados}

Para la discusión de los resultados se tomaron como base las siguientes categorías de análisis: proceso de transición, proceso formativo y transición de preescolar a primaria.

Los resultados obtenidos en esta investigación parten de cada objetivo específico planteado. Para empezar, está la descripción del proceso de transición de educación inicial a básica primaria, en la que se pudo evidenciar varios aspectos gracias a una entrevista semiestructurada dirigida a una docente de primaria; uno de ellos da respuesta a una de las preguntas dirigidas a la docente, dando cuenta de la preparación de los estudiantes.

No, no; los niños no tienen una preparación, ellos pasan derechito al otro grado, a lo que fue, fue. (Profesional entrevistada n. ${ }^{\circ} 1,9$ de marzo de 2018)

De forma similar, otra maestra entrevistada agregó lo siguiente:

[...] a decir verdad, los niños pasan a primerito y luego allí es que uno viene los prepara desde lo temático para los niveles que vienen. (Profesional entrevistada n. ${ }^{\circ} 3,9$ de marzo de 2018)
Con base en los testimonios anteriores, se pudo apreciar que los niños y niñas no cuentan con una preparación para hacer este tránsito, tales como actividades de sensibilización o adaptación para enfrentar estos cambios. Ligado a esto, el proceso de adaptación en esta transición —más que afectar a los niños y niñas - fue un proceso más complejo para la docente y padres de familia, pues por una parte se tuvieron que hacer ciertos cambios en la metodología; y, de igual forma, con los padres, en el sentido de que son nuevas responsabilidades y se exige un mayor acompañamiento de ellos hacia sus hijos. Sobre estas dinámicas referentes a pasar de una etapa a otra, se menciona que "proporcionar pautas para mejorar este proceso de transición es una tarea compleja que debe ser llevada a cabo teniendo en cuenta todas las variables (académicas y no académicas) que rodean al sujeto" (González et al., 2019, p. 85).

Si bien la transición no es un factor que influya directamente en el desarrollo de los estudiantes, se hace necesario no dejarla pasar desapercibida, debido a que es importante garantizar un proceso completo en los niños y niñas de la institución educativa donde se logre culminar totalmente una etapa y se esté preparado para empezar una nueva. En una investigación realizada en el año 2015, Ilamada Expectativas infantiles acerca de la transición escolar entre educación infantil y educación primaria, se pudo encontrar semejanzas en los resultados obtenidos, rescatando que: "Tras el análisis de las entrevistas los dibujos se considera que hay aspectos de la educación primaria que los niños/as conocen y otros que no" (Garribia, 2015, p. 38). De esta forma, se puede discernir que, para los diferentes contextos, es necesario aplicar algunas estrategias que ayuden a los estudiantes a resolver sus dudas y a tener una adaptación más eficaz a la hora de enfrentar estás nuevas etapas en las que se encontrarán con ambientes diferentes, otros profesores e inclusive, nuevos compañeros de curso. Todo esto ayudando a tener una mejor confianza en los niños y niñas que pasan de la educación inicial a la básica primaria.

De forma análoga, en el proceso de transición el colegio ha demostrado que permite el tránsito de los niños y niñas de un grado a otro, realizando reuniones generales con los padres y madres y 
cumpliendo con el debido proceso de matrícula y promoción. Sobre este aspecto, una de las maestras entrevistadas respondió:

La institución hace reuniones con los padres de familia antes de iniciar el año escolar, como para dar a conocerse con la profesora, y ya. (Profesional entrevistada n. ${ }^{\circ} 2,9$ de marzo de 2018)

Asimismo, otra docente afirmó:

[...] aquí en el colegio lo que se hace es citar a los acudientes para comentarles sobre los profes que van a tener sus hijos y el material con el que se va a trabajar en adelante. (Profesional entrevistada n. ${ }^{\circ}$, 9 de marzo de 2018)

Se evidenció de esta manera que aquí no se tuvieron en cuenta otros aspectos que podrían influir de forma significativa en dicha transición; como las nuevas formas de interacción que tendrían los estudiantes basándose en la manera en cómo estos y estas estarán sentados individualmente en el aula de clase, al igual que los espacios en donde tendría lugar los recreos. Asimismo, los cambios e impactos comportamentales que representaría la estructuración de nuevas asignaturas para los niños y niñas, del mismo modo que las nuevas dinámicas evaluativas tales como presentaciones públicas orales, trabajos grupales asignados por los docentes, exámenes individuales, entre otros. Por esta razón, se hace necesaria la formación en el trabajo con padres y acudientes; puesto que la familia no es un ente aislado, sino más bien es un engranaje que se articula al proceso de los niños y niñas en la escuela. Y si se mira de soslayo este componente, el quehacer de enseñanza y aprendizaje no se estaría desarrollando de forma óptima, conforme a lo que se propone desde un enfoque educativo; conexión familia, escuela y sociedad:

Por eso, cada vez será más importante la formación del docente en el trabajo con padres, para que comprenda la constitución de la subjetividad humana y el manejo de la transferencia; pues si bien el docente no es un clínico y su objeto de atención no es el inconsciente, se tiene que ver con él diariamente en su cotidianidad, desde los comportamientos y actitudes que presentan niños y adultos. (Ramírez et al., 2015, p. 112)

Además, hay factores importantes que enfrentan los estudiantes a la hora de pasar de un grado a otro, como la incertidumbre de lo que puede ocurrir en este nuevo ambiente y la comodidad que sientan en este. En relación con esto, se encontró una investigación realizada en Bogotá, durante los años 2011-2012, denominada El proceso de adaptación escolar y el desempeño académico como apuesta para la calidad educativa por Campo et al., en la cual se encuentra como resultado y conclusión que:

La adaptación de los estudiantes a las nuevas situaciones que se presentan en las etapas de la vida escolar y específicamente cuando inician el bachillerato, inducen en las actitudes, valores, saberes y habilidades que se construyen a lo largo de su vida, permitiendo el éxito en lo personal, familiar, social y escolar. (2012, p. 50)

Por consiguiente, es importante relacionar a los niños y niñas en diferentes contextos desde el inicio de su vida escolar, facilitando así la adaptación en nuevos espacios de aprendizaje, y haciendo más ameno el proceso de la transición escolar para ellos. Además, se generan más seguridades al afrontar todas las transiciones que requieren el ámbito educativo para la vida.

Asimismo, de la categoría del proceso de transición con relación a la formación integral de los niños y niñas se evidenció que —durante las sesiones de observación no-participante y el análisis documental - tanto docentes como padres de familia desempeñaron papeles muy importantes e indispensables durante el paso de educación inicial a básica primaria. En primera instancia, las diversas características propias de cada grado simbolizaron un cambio desde la rutina escolar hasta los contenidos a enseñar, lo cual usualmente causa inseguridad a todos los agentes implicados. Se observó, además, que claramente las docentes de preescolar utilizaron metodologías muy diferentes a la docente de primaria, lo que se convierte en una dificultad 
más al pasar entre estos grados, así como se identificó en uno de los testimonios dados por una docente titular del grupo de primero de primaria:

La adaptación ha sido un poco difícil ya que las profes que estaban en transición tenían un tono de voz un poco más bajo, el cantar o si levantaban su tono de voz, no se iba a sentir tan fuerte como el mío; cuando yo llego por primera vez a saludar y me escuchan ese vozarrón, para ellos fue "la profe nos está regañando", entonces claro ya ellos venían de una profe calmada, entonces lo primero que ellos dijeron "profe no nos regañe, ¿qué hicimos?" entonces fue como explicarles. La adaptación más que todo fue la mía hacia ellos, para que ellos pudieran sentirse bien, que ellos vieran que la profe no era mala carosa ni estaba regañando. (Profesional entrevistada n. ${ }^{\circ} 3,9$ de marzo de 2018)

De forma similar, otra docente manifestó:

[...] primero se ve, cómo cualquier grupo nuevo, que son tímidos; pero si es verdad que hay que explicarles cosas desde la actitud que ya no se hacen en primero y que ellos hacían en el grado anterior. (Profesional entrevistada n. ${ }^{\circ}$, 9 de marzo de 2018)

Las diferencias entre un grupo y otro son evidentes pero necesarias; por lo que es claro que no puede permanecer una metodología infantilizada en la escuela. Sin embargo, es indispensable que el docente logre minimizar el intervalo de diferencia para brindar seguridad a sus alumnos, facilitando la transición a un nuevo grado y, al mismo tiempo, creando conciencia de sus nuevas responsabilidades y metodologías. Sobre la influencia que tienen los docentes y acudientes en este proceso de transición se presenta lo siguiente:

Pero, no sólo el conocimiento de experiencias vividas por otros iguales puede determinar o, al menos influir, de forma positiva o negativa en el logro de una adecuada transición escolar de los niños; la influencia de los referentes adultos (familiares y profesores) $-y$ los mensajes que éstos aportan — se convierten en referentes fundamentales para el logro de una adecuada transición. (Castro et al., 2015, p. 44)
Por otra parte, una investigación realizada en la ciudad de Bogotá titulada Prácticas evaluativas: transiciones del grado preescolar a primaria, afirma en sus resultados sobre la inseguridad que genera en los niños y niñas pasar de su aula de preescolar al salón de primaria que:

El proceso de transición de preescolar a primaria es bastante difícil y es un cambio de vida total ya que muchos de los niños que pasan a primero no están preparados emocionalmente para este cambio, porque no se sienten protegidos y no sienten el mismo trato en este grado, las docentes afirman que muchos de los niños son afectados por este cambio tan drástico ya que no solo cambia el horario, de salón, los baños, los cuidados; sino que cambian su forma de aprender, ya que en primero las clases son más magistrales y poco lúdicas. (Caicedo, 2016, p. 82)

Así pues, el docente de primaria debe lograr que todas estas modificaciones entre un grado y otro puedan ser lo más implícitas posibles, garantizando a los niños y niñas un ambiente cómodo, seguro y que potencie su aprendizaje. Es por esto por lo que se evidenció que la actitud del profesor tiene un gran peso a la hora de la adaptación de los infantes, pues si es permeado por todas las dudas que el proceso de transición implica, no estaría en condiciones adecuadas para brindar la estabilidad a sus nuevos estudiantes; y, por ende, estos no crearan una buena relación socio-afectiva.

Otro de los resultados significativos rescatado durante una de las sesiones de observación no-participante fue en torno a las expectativas de los estudiantes frente a los cambios que experimentaron. Los estudiantes del grado primero expresaron gran comodidad y seguridad respecto a sus nuevas responsabilidades, demostrando, además, un gran sentido de pertenencia por los nuevos espacios del aula de clase, su propio pupitre y las diferentes materias que cursan. Esto hace que se desprenda en el niño unas bases de autonomía e interés, siendo esto de vital importancia para que se dé un proceso de adaptación asertivo. Sobre este aspecto, entre otros, se presenta lo siguiente:

El proceso de transición es percibido por los maestros como un proceso de desarrollo madurativo que 
requiere adaptarse a un nuevo entorno. Para las familias, implica la disminución de la dependencia del niño respecto a la madre o al padre. Así mismo, los adultos discrepan en el concepto "estar preparado". El alumnado desea conocer el nuevo entorno educativo, los maestros o las nuevas normas escolares antes del inicio del curso con el fin de desarrollar un sentimiento previo de pertenencia. (Martínez, 2018, p. 144)

Además, los estudiantes afirmaron y expresaron en sus dibujos para el mural de situaciones (actividad desarrollada durante una sesión de observación) que no extrañaban el grado anterior; lo recordaban con buenos momentos y fuertes sentimientos hacia sus compañeros y docente; no obstante, preferían recibir sus nuevas clases en el salón de primero. De manera análoga, una investigación realizada en el año 2016, en la ciudad de Bucaramanga, en la cual hablan del desarrollo y desempeño escolar mediante una propuesta pedagógica para la articulación de preescolar y primero, concluye en sus resultados que los niños de primero se caracterizan por su actitud de madurez con el nuevo espacio:

Los niños de primero ven el paso como algo significativo porque los tratan como a los grandes de la institución, ya pueden asistir a otros espacios que están restringidos para los chicos de preescolar, pueden compartir juegos y espacios delimitados para los grandes, además de compartir la formación y las buenas tardes con los demás grupos. (Acuña, 2016, p. 68)

Si bien la transición acarrea diversos cambios metodológicos, como la forma en que se lleva a cabo una clase, cómo se percibe al enseñar y cómo se evalúa. De igual forma, en cuanto a los cambios espacio-temporales, como la asignación de puestos individuales, la ambientación de los salones y las zonas en las que se toma el recreo es necesario mencionar que en sí influyen en cierta manera desde el punto de vista emocional (ya sea de forma positiva o negativa) a los pequeños. A su vez, también es verídico que por medio de estas modificaciones es posible que se potencie cada una de las capacidades de los niños, sin llegar a afectar sus habilidades sociales; ya que les proporciona espacios que estimulan su autonomía y autodependencia, logrando que poco a poco los estudiantes sientan más seguridad en sí mismos, y con muchas más herramientas para enfrentar nuevas situaciones, tanto académicas como personales. Esta apreciación se notó durante las sesiones de observaciones no-participantes que se desarrollaron con las unidades de análisis.

Por último, uno de los aspectos más recurrentes y necesarios - tanto en el proceso de transición como en el proceso formativo de los estudiantesque se pudo evidenciar durante las sesiones de observación no participante y el análisis documental de reportes pedagógicos fue el acompañamiento familiar. La actitud de los padres de familia tiene un gran alcance en el desarrollo del niño o la niña que se enfrenta al paso de un grado a otro. Claramente, durante todo el proceso formativo de los estudiantes, es indispensable lograr una articulación entre escuela, familia y comunidad a través de reuniones más periódicas y actividades extracurriculares que involucren a dichos actores en espacios académico-comunitarios. A su vez, se hace también necesario la participación de la escuela y la sociedad en el uso adecuado de las redes sociales para compartir información e informar a la comunidad educativa sobre las realidades del proceso educativo de los niños y niñas, pues son estos tres los ambientes en donde el infante interactúa permanentemente, y de los cuales debe obtener una enseñanza significativa que aporte a su desarrollo integral. En caso de no haber una conexión, en este caso de los padres de familia con la escuela, existe la probabilidad de que se presenten algunas dificultades que obstaculicen la comodidad del niño en su nuevo grado, como lo expresó una de las docentes de primaria:

En parte ellos no van a estar de acuerdo con la pedagogía que muchas veces uno implementa, dicen como: "profe es que usted no explica bien", "es que el niño mío le tiene miedo". Entonces es como ellos también inculcando de que la profe es mala, de que las personas alrededor son malas cuando dicen: "vas a ir pero no vas a prestar los colores porque te los roban", le estamos colocando un pare al niño de que se 
debe cuidar de sus mismos compañeros. (Profesional entrevistada n. ${ }^{\circ} 1,9$ de marzo de 2018)

Por lo anterior, es evidente que la ansiedad y la angustia que experimentan los padres de familia aumentan al pasar a un nuevo grado, transmitiendo a sus hijos dicha inseguridad y temor frente a estas nuevas situaciones, lo que causará, entonces, que el desenvolvimiento del estudiante frente su proceso de adaptación se presente de manera confusa y difícil, tanto para la institución como para el estudiante y sus acudientes. Una investigación realizada en la ciudad de Bogotá en el 2008 sobre las expectativas que tienen los niños, los padres, los maestros y los directivos docentes frente a las transiciones, explaya unos resultados análogos a este estudio, en donde el autor plantea que:

A partir del trabajo de campo se confirma que efectivamente las respuestas de los padres de familia expresan que las transiciones los movilizan con preocupaciones por la capacidad de sus hijos de adaptarse al cambio y si les ira bien frente al vínculo con la profesora. (Abello, 2008, p. 131)

Ahora bien, es clara la imperante necesidad de la articulación entre la institución y los padres de familia para poder brindar todas las herramientas que requiere un estudiante al momento de su transición al siguiente grado. Siendo de vital importancia que padres y madres se despojen de cada una de sus preocupaciones para así aportar de manera significativa a dicho tránsito.

\section{Conclusiones}

- Si bien los procedimientos que realiza la institución posibilitan el tránsito, es necesario que se tenga en cuenta la implementación de jornadas de sensibilización con los niños y niñas que ayuden a disminuir los niveles de ansiedad y lograr una mejor adaptación, evitando dificultades que se pueden presentar al afrontar dicho cambio.

- El hecho de pasar de un grado a otro trae consigo el cambio de metodología de la maestra. Esto incide a su vez en la forma de comunicación de los estudiantes, haciéndolo visible en básica primaria, donde se disminuye la interacción con los pares, pero a su vez aumenta en relación con la docente.

- Los niños y niñas en este nuevo grado de básica primaria adquieren habilidades en cuanto a su independencia escolar y personal, lo que significa que la transición desde educación inicial no afecta directamente al estudiante; al contrario, es una herramienta que potencia su desarrollo integral.

- Los padres de familia desempeñan un papel fundamental durante las transiciones escolares, debido a que son ellos los que influyen directamente en la actitud que toman los estudiantes a iniciar el nuevo grado.

- En estas transiciones escolares los padres y madres suelen permearse de dudas y ansiedades ante el nuevo proceso que sus hijos enfrentan, por esto es por lo que es necesario un acompañamiento permanente que apunte a la sensibilización con las familias, ayudando a disminuir todos los interrogantes que se puedan presentar en el proceso académico.

\section{Referencias}

Abello, R. (2008). Transiciones al inicio de la escolaridad en una institución educativa de carácter privado en Bogotá: Una experiencia de construcción de sentido (tesis de doctorado). Universidad de Manizales.

Acuña, L. E. (2016). Desarrollo y desempeño escolar mediante una propuesta pedagógica para la articulación de preescolar y primero (tesis de maestría). Universidad Cooperativa de Colombia.

Bácares, C. (2018). Los derechos de los niños, niñas y adolescentes: una reflexión sobre las resistencias, fenómenos y actores que los modulan, determinan y aplazan en América Latina. Infancias Imágenes, 18(1), 51-67.

Bustamente, R. L., Cifuentes, L. M., Martínez, G. L., Jaramillo, V. B., Cardona, M. N., Jiménez, H. S. y Fernández, Y. S. (2019). ¿Qué y cómo le digo? Saberes y concepciones de docentes en educación preescolar sobre el trabajo con padres. En M. Córdoba (ed.), Gestión del conocimiento perspectiva multidisciplinaria (vol. 12, pp. 373-386). Fondo Editorial Universitario de la Universidad Nacional Experimental Sur del Lago Jesús María Semprum. 
Caicedo, J. I. (2016). Practicas evaluativas: transiciones del grado preescolar a primaria (tesis de pregrado). Pontifica Universidad Javeriana.

Campo, A., Castaño, V. y Valencia. M. (2012). El proceso de adaptación escolar y el desempeño académico como apuesta para la calidad educativa (tesis de pregrado). Universidad de Manizales.

Castro, A., Argos, J. y Ezquerra, P. (2015). La mirada infantil sobre el proceso de transición escolar desde la etapa de educación infantil a la de educación primaria. Perfiles Educativos, 37(148), 34-49.

Castro, A., Ezquerra, M. P. y Argos, J. (2017). Fundamentos teóricos de la Educación Infantil. Universidad de Cantabria Ediciones.

Dunlop, A. y Fabian, H. (eds.) (2007). Informing Transitions in the Early Years. MacGraw-Hill.

Garribia, F. (2015). Expectativas infantiles acerca de la transición escolar y educación primaria. Comunidad autónoma de Cantabria.

González, D., Vieira, M. J. y Vidal, J. (2019). Variables que influyen en la transición de la educación primaria a la educación secundaria obligatoria. Un modelo comprensivo. Bordón. Revista de Pedagogía, 71(2), 85-108. https://recyt.fecyt.es/index.php/ BORDON/article/view/73020

Legañoa, A. J., Soler, H. M., Souto, N. Y., Alonso, M. C. y Castellano, Z. M. (2018). Valoración del proceso docente educativo del internado de la carrera de Estomatología en Camagüey. Humanidades Médicas, 18(3), 455-468.

López, D. (2013). Los lenguajes artísticos y el contexto cultural como mediadores pedagógicos y sociales. Infancias Imágenes, 12(2), 48-59.

Martínez, S. S. (2018). Investigaciones sobre la transición a educación primaria: la mirada infantil a examen. Revista de Investigación en Educación, 16(2), 136-152.
Ortiz, M. S. (2015). Estrategias didácticas empleadas por los docentes en la transición escolar entre los niveles de educación inicial y primaria del NER 295, Municipio Arístides Bastidas, Estado Yaracuy. Revencyt, 20, 45-61.

Peñuela, D. M. (2013). Infancia-vacío: entre las 'revoluciones' escolar y sentimental. Infancias Imágenes, 12(1), 60-69.

Perafán, L. (2004). Análisis del discurso: procesos formativos e investigaciones lingüísticas. Universidad del Cauca.

Ramírez, L. E., Quintero, S. R. y Jaramillo, B. (2015). Formación en el trabajo con familias para la educación de la primera infancia. Zona Próxima, 22, 105-115.

Rivera, J. A. S. (2018). Los fundamentos del enfoque cualitativo en la innovación de la enseñanza geográfica. Didáctica de las Ciencias Experimentales y Sociales, 35, 33-44.

Rodríguez, Y. J. y Álvarez, E. (2018). La transición educativa del Centro de Desarrollo Infantil al grado preescolar en Caucasia, Antioquia: ¿un proceso o un paso? Infancias Imágenes, 17(1), 67-77.

San Fabián, J. L. (2007). Coordinación entre primaria y secundaria ;Ojo al escalón! Universidad de Oviedo.

Turra, D. O. (2017). Racionalidades curriculares en la formación del profesorado de historia en chile. Diálogo Andino, 53, 23-32.

Valdivia, M., Manrique, L. M. y Fonseca, V. (2018). Las Características de la transferencia positiva del español en el aprendizaje de FLE. CIEX Journ@l, 6(6), 29-36.

Vloger, P., Crivello, G. y Woodhead, M. (2008). La investigación sobre las transiciones en la primera infancia: análisis de nociones, teorías y prácticas. Bernard van Leer Foundation. 